\title{
Dolor y autoexplotación en la era digital
}

\section{Pain and self-exploitation in the digital era}

\author{
DUNE VALLE JIMÉNEZ \\ Universidad Sergio Arboleda
}

Recibido: 04-12-2018

Aceptado: 20-12-2018

\begin{abstract}
RESUMEN
En este escrito nos proponemos mostrar la relación estrecha entre la problemática técnica y la vivencia histórica del dolor, propia de la era digital, en la que el sufrimiento es un sentimiento que se intenta negar o disfrazar. Desde nuestra perspectiva comprendemos el dolor como una experiencia fundamental que es importante asumir y vivir de forma cabal pues nos abre de manera originaria al mundo que nos rodea y a nosotros mismos. Para llevar a cabo esta tarea tomaremos en cuenta la interpretación de Nietzsche y Jünger, quienes sostienen que el dolor tiene un carácter interpretativo epocal, esto nos lleva a reconocer la figura propia del dolor en la era de la técnica, donde se pretende ocultar esta experiencia con una apariencia de seguridad y confort que nos brindan la técnica, lo que se agudiza en la era digital con la autoexplotación y optimización de la existencia que denuncia Byung Chul Han.

\section{PALABRAS CLAVE}

DOLOR, TÉCNICA, TRABAJO, ERA DIGITAL, AUTOEXPLOTACIÓN.
\end{abstract}

\begin{abstract}
This article intends to show the close relationship between the problem of technique and the historical experience of pain, typical of the digital era, in which suffering is commonly denied or concealed. From our stance, pain is a fundamental experience that should be embraced because it connects us directly with the world and ourselves. In order to carry out this task, we will discuss the proposals of Nietzsche and Jünger, who argue that pain has an epochal interpretative character. Thus, while in the age of technique pain is usually hidden behind an appearance of
\end{abstract}


security and comfort, precisely provided by technique, in the digital era this is exacerbated with the self-exploitation and the optimization of existence, as denounced by Byung Chul Han.

KEYWORDS

PAIN, TECHNIQUE, WORK, DIGITAL ERA, SELF-EXPLOITATION.

\section{INTRODUCCIÓN}

EL PRESENTE TRABAJO aborda el dolor entendido como una experiencia fundamental de la existencia que nos abre al mundo, a la relación con los otros y a nosotros mismos de forma privilegiada. Es decir, el dolor se concibe como ese sentimiento o afecto que nos revela el mundo en su dimensión más profunda y prístina. Es indiscutible que esta experiencia fundamental ha acompañado al hombre desde el nacimiento de la humanidad, sin embargo, siguiendo a Nietzsche y Jünger, podríamos afirmar que el dolor no es algo ahistórico, o ajeno a las circunstancias del tiempo donde se manifiesta, sino que tiene un carácter interpretativo y lo que pretendemos es reconocer la manifestación histórica del dolor en la contemporaneidad. Esto teniendo en cuenta que nuestra relación con el dolor se transforma en la era de la técnica, donde la servidumbre del hombre con los objetos técnicos modifica radicalmente su relación con el dolor, adquiere así una figura peculiar en la era digital, pues justamente esta modulación del dolor en la contemporaneidad trata de ser ocultada o disfrazada continuamente con la comodidad, confort y aplicaciones de las nuevas tecnologías, las que han prometido dar solución a cualquier tipo de problema de la humanidad. Sin embargo, ahí es donde precisamente se esconde el dolor del hombre contemporáneo, donde se transforma en un dato cuantificable sometido a las autoexigencias de la optimización que la sociedad digital le impone y que él termina por hacer suyas y autoimponerse. En definitiva, nos proponemos preguntar cómo se experiencia el dolor en la era digital y para llevar a cabo este trabajo recogeremos los aportes de Friedrich Nietzsche, Ernst Jünger, Zygmunt Bauman y Byung Chul Han.

\section{El DOLOR COMO INTERPRETACión EN LA FILOSOFÍA DE NieTZSChe}

Sería conveniente al empezar este apartado aclarar por qué hemos circunscrito nuestro trabajo a la experiencia del dolor en la era de la técnica, o más específicamente en la era digital, pues puede plantearse la idea de por qué no expandir o ampliar el ámbito de la pregunta al dolor en general. Esta acotación de la investigación tiene en cuenta el carácter histórico ontológico del dolor como manifestación primordial de un contexto histórico epocal.

Una de las citas más celebres de Nietzsche, recogida en los Fragmentos Póstumos dice: «"Solo hay hechos" yo diría: no, precisamente no, precisamente no hay hechos, sino solo interpretaciones. No podemos constatar ningún hecho "en s'́"; tal vez sea un absurdo querer algo por el estilo. "Todo es subjetivo", 
decís; pero ésta es ya una interpretación, el «sujeto» no es nada dado, es solo algo añadido por la imaginación, algo añadido después. ¿Es, en fin, necesario poner todavía al intérprete detrás de la interpretación? Ya esto es invención, hipótesis»». ${ }^{1}$ Esta interpretación nietzcheana que pone en tela de juicio uno de los pilares de la cultura occidental, la verdad objetiva, abre una nueva perspectiva en la forma de comprender el mundo y nuestra forma de relacionarnos con el dolor de forma histórica y cultural. Más aún, hablar de Nietzsche y su filosofía conlleva hablar de una vida y un pensamiento signado por el dolor y el sufrimiento; por todos es sabido que sufrió a lo largo de su vida graves enfermedades y padecimientos que sin lugar a dudas marcaron a fuego su pensamiento filosófico.

Afirman algunos comentadores que una existencia sufriente fue determinante para plasmar aquellos pensamientos que hicieron tambalear los cimientos de la cultura contemporánea: la muerte de Dios, la transvaloración de todos los valores, el carácter interpretativo de la verdad, la genealogía de la moral, el superhombre, el nihilismo, son todos ellos conceptos e interpretaciones que en gran medida están atravesados por dichas experiencias. Podríamos escribir muchas teorías respecto a esta relación entre el dolor que experimentó Nietzsche en su vida y la correlación de estas experiencias en su filosofía, sin embargo hemos optado por leer en sus textos sus interpretaciones del dolor y el sufrimiento, entendidas principalmente como una interpretación epocal del dolor, pues este sentimiento, afecto se experiencia de diferentes maneras dependiendo del contexto histórico, es decir, también es una interpretación.

Como recuerda Ocaña, en Sobre el dolor, Nietzsche en los Fragmentos Póstumos, insiste en la idea de que el dolor es el producto de una interpretación intelectual y axiológica. Esto significaría que la experiencia del dolor estaría profundamente influenciada por interpretaciones y prejuicios y no por realidades metafísicas puras o fenoménicas. En estos prejuicios o interpretaciones se fundamenta muchas veces la tendencia a calificar el dolor como malo o negativo. ${ }^{2}$ En este sentido afirma Nietzsche «El placer y el dolor no son, en modo alguno cosas inversas. - El dolor es un proceso intelectual en el que el juicio eleva la voz de la decisión-, el juicio "nocivo", en que se resume una larga experiencia. En sí, el dolor no existe. No es la lesión, la que hace daño; es la experiencia de las malas consecuencias que una lesión puede tener para todo el organismo, la que habla en la figura de esa onda conmoción llamada dolor». ${ }^{3}$

Bajo este prisma se muestra el dolor como una experiencia históricamente interpretativa, que varía según los derroteros culturales e históricos que va to-

1 Nietzsche 2008, p.222.

$2 c f$. , Ocaña 1997, p. 213-214.

3 Nietzsche 2008, p. 594. 
mando la humanidad, por eso es que a la era de la técnica y, específicamente, en la era digital se experiencia un dolor peculiar, que sería el signo de los tiempos.

Nietzsche concibe el dolor, no como una experiencia más entre otras o como un sentimiento que deberíamos evitar y despreciar como un añadido accidental y pasajero que no puede decir mucho de la existencia, esto es, del carácter esencial de la vida y especialmente del cuerpo, sino que es entendida más bien como esa experiencia que nos muestra el nudo hecho de ser, donde el hombre va templando su carácter y su propio ser y por tanto no puede ser una experiencia que se deba evitar, ocultar, narcotizar para aplacarla. Como comenta Nietzsche: «el sufrimiento mismo es considerado por ellos como algo que hay que eliminar. Nosotros los opuestos a ellos, que hemos abierto nuestros ojos y nuestra conciencia al problema de en qué lugar y de qué modo la planta "hombre" ha venido creciendo de la manera más vigorosa hacia la altura, opinamos que esto siempre ha ocurrido en condiciones opuestas, opinamos que, para que esto se realizase, la peligrosidad de su situación debió aumentar antes de manera gigantesca... hasta convertirse en algo sutil y temerario, que su voluntad de vida tuvo que intensificarse hasta la voluntad incondicional de poder». ${ }^{4}$

Ahora bien, esta voluntad de poder de la que habla Nietzsche se instala en el mundo contemporáneo, según la interpretación de Heidegger, como voluntad de dominio del ente en su conjunto, del ente llamado hombre y la naturaleza, que pretende explotar todo de forma incondicionada; esto es, el mundo entero es sometido y se transforma en objeto de su dominio. ${ }^{5}$

Según Nietzsche el dolor vendría a ser algo así como una fuerza vital que permite el desarrollo y la evolución del hombre que se construye principalmente a través del sufrimiento, de las experiencias dolorosas que lo van construyendo y templando; es por eso que el hombre no las debe evitar sino precisamente aceptarlas en su carácter eterno, quererlas una y otra vez, pues ellas son las llaves que nos permiten la relación auténtica con la realidad, con la época histórica que nos toca vivir y a la cual estamos destinados.

Esto lo reafirma en Así habló Zaratustra cuando sostiene que:

El dolor es también placer, la maldición es también bendición -idos o aprenderéis: un sabio es también un necio.

¿Habéis dicho sí alguna vez a un solo placer? Oh amigos míos, entonces dijiste sí también a todo dolor. Todas las cosas están encadenadas, trabadas, enamoradas. Todo de nuevo, todo eterno, todo encadenado, trabado, enamorado, oh, entonces amasteis el mundo

4 Nietzsche 1993, p. 69.

5 Cf., Heidegger 2000, p. 206. 
Vosotros eternos, amadlo eternamente y para siempre: y también al dolor decidle: ¡pasa pero vuelve! Pues todo placer quiere eternidad. ${ }^{6}$

En definitiva, Nietzsche con su interpretación del dolor reconoce, en primer lugar, la importancia y radicalidad de los sentimientos para dar cuenta del mundo, del carácter histórico de la vida humana y de su experiencia del sufrimiento, del dolor, como fenómeno privilegiado para pensar el tiempo que nos toca vivir. El dolor es aquella experiencia que intenta esconder, evitar, disfrazar, el hombre contemporáneo, pero que siempre está ahí, acompañándolo, desde su nacimiento hasta su muerte, $y$, esto, desde los albores de la humanidad. A juicio de Nietzsche, en vez de ocultar esta experiencia, lo que debemos hacer, es amarla, querer que se repita una y otra vez hasta la eternidad, pues ella es la llave que nos abre al mundo. Todo esto queda expuesto con absoluta claridad en el parágrafo 341 de La ciencia jovial, donde expresa por vez primera su formulación del eterno retorno: "Qué te sucedería si un día o una noche se introdujera furtivamente un demonio en tu más solitaria soledad y te dijera: "Esta vida, así como la vives ahora y la has vivido, tendrás que vivirla una vez más e innumerables veces más; y nada nuevo habrá allí, sino que cada dolor y cada placer y cada pensamiento y suspiro y todo lo indeciblemente pequeño y grande de tu vida tendrá que regresar a ti, y todo en la misma serie y sucesión - e igualmente esta araña y este claro de luna entre los árboles, e igualmente este instante y yo mismo. El eterno reloj de arena de la existencia será dado vuelta una y otra vez - ¡ y tú con él, polvillo de polvo!"»». ${ }^{7}$ Como se puede apreciar aquí, Nietzsche cuando formula su doctrina del eterno retorno, que viene a significar una afirmación de la vida y del destino, frente a la negación y las promesas transmundanas, tiene en cuenta al dolor, como aquella experiencia que precisamente define a la existencia y la marca de forma preeminente. Justamente una de las cosas que Nietzsche tiene en cuenta para graficar el significado de este pensamiento es el dolor, como aquello que no debemos negar sino precisamente afirmar y querer que retorne eternamente, pues es inseparable de la dicha, la felicidad y el placer. Esta idea podría graficarse en lo que plantea en Más allá del bien y del mal, cuando señala que «iparece cabalmente que nosotros preferimos que el sufrimiento sea más grande y peor de lo que ha sido nunca... ¡La disciplina del gran sufrimiento - ¿No sabeís que únicamente esa disciplina es la que ha creado hasta ahora todas las elevaciones del hombre? Aquella tensión del alma en la infelicidad, que es la que le inculca su fortaleza, los estremecimientos del alma ante la espectáculo de la gran ruina, su inventiva y valentía el soportar perseverar, interpretar y aprovechar la

6 Nietzsche 2004, 436

7 Nietzsche 1985, p. 200. 
desgracia, así como toda la profundidad, misterio, máscara, espíritu, argucia, grandeza que le han sido donados bajo sufrimiento - ¿no le han sido donados bajo sufrimiento, bajo la disciplina del gran sufrimiento?». ${ }^{8}$

En efecto, Nietzsche nos dice que debemos desear y querer eternamente, tanto el dolor como el placer, entendidas como aquellas experiencias que nos constituyen de forma indefectible; estas afirmaciones muestran un indicio de la importancia capital que tiene el dolor en el entramado de la filosofía nietzscheana, que como corolario viene a afirmar la suprema disciplina, que es la disciplina del gran sufrimiento.

\section{ERNST JÜNGER: LA EXPERIENCIA DEL DOLOR EN LA ERA DE LA TÉCNICA}

Sin lugar a duda, para referirse a la época de la técnica y su relación con el dolor es inevitable tener en cuenta la figura de Ernst Jünger, quien en 1934 escribió un ensayo titulado Sobre el dolor (Über den Schmerz), donde interpreta precisamente como se experiencia a comienzos del presente siglo la relación del hombre con el dolor. Sin lugar a dudas la experiencia que expone Jünger está marcada por su presencia en el campo de batalla en la Primera Guerra Mundial. Esto quiere decir que su interpretación está marcada a fuego por su experiencia con los horrores que le son consustanciales al desarrollo de la maquinaria bélica y su capacidad de destrucción de millares de seres humanos. Esto le muestra de forma destacada el surgimiento de un nuevo estadio de la humanidad denominado la era de la técnica. En este contexto pudo comprobar que los avances de las técnicas no son directamente proporcionales al progreso de la humanidad, pues si bien la Ilustración y la Modernidad habían hechos estas promesas, del progreso y bienestar de la humanidad gracias al desarrollo técnico científico, en el siglo XX nos encontramos con una realidad bastante distinta.

Es importante destacar que Jünger, al igual que Nietzsche, reconoce que cada época histórica tiene una relación distinta con el dolor, es decir, este es experienciado de distintas maneras. Teniendo esto en consideración es que Jünger viene a comentar que: «como criterio el dolor es inmutable; variable es, en cambio, el modo, la manera como el ser humano se enfrenta a él. Con cada una de las mudanzas significativas que acontecen en su temple básico se modifica la también la relación del ser humano con el dolor...se sustrae a la conciencia, pero constituye la mejor piedra de toque para conocer una raza. En nuestro tiempo cabe observar bien este hecho, pues ya disponemos de una relación nueva con el dolor, sin que todavía no le estén dadas a nuestra vida una normas absolutamente vinculantes»». ${ }^{9}$ Lo que nos viene a decir Jünger es que si queremos aproximarnos de la mejor forma posible a esta nueva figura

8 Nietzsche 1993, p. 171-172

9 Jünger 1995, p. 14. 
del hombre que surge en la era de la técnica, debemos necesariamente tomar en cuenta esta nueva relación que se establece con el dolor, es decir, preguntar cómo el hombre de la técnica se enfrenta a él. Asimismo, deja claramente establecida la importancia del dolor como experiencia reveladora de la época presente, lo que no quiere decir que la radicalidad de esta experiencia varíe con el tiempo, pues siempre se considera como un criterio ontológico privilegiado para comprender el mundo en las distintas etapas de la historia. Y lo esencial de todo esto es que quizás esa relación nueva con el dolor permanece oculta para gran parte de la humanidad, que ni siquiera han entendido o comprendido las transformaciones radicales a las que se enfrenta la humanidad por este nuevo escenario dominado por la técnica.

Para el pensador alemán el dolor sería la piedra de toque de la realidad, que nos abre de forma originaria a nuestro horizonte histórico y a nuestro propio ser, como «una de esas llaves con que abrimos las puertas no solo de lo más íntimo, sino a la vez del mundo» y agrega más adelante «una circunstancia que intensifica extraordinariamente el acoso del dolor es la nula atención que él presta a nuestros órdenes de valores [...] no hay ninguna situación humana que tenga un seguro contra el dolor» ${ }^{10}$ es evidente la importancia que posee el dolor para Jünger, pues, al igual que Nietzsche, interpreta esta experiencia como una de carácter fundamental que nos abre a nosotros mismos, ya que desde la relación con el dolor que establecemos de forma epocal es posible desentrañar el mundo y sus articulaciones, por eso, afirma Jünger, sería la piedra de toque de la realidad, que nos muestra el mundo en su carácter originario. Tan radical es esta propuesta jungeriana que incluso llega a afirmar que nuestra experiencia y relación con el dolor es aquello que define a la existencia, define nuestro propio ser, teniendo esto en cuenta es que concluye: «iDime cuál es tu relación con el dolor y te diré quién eres!». ${ }^{11}$

En este sentido, sostiene Jünger que para lograr una caracterización del dolor debemos en primer lugar dejar claro que «la persona singular se afana por relegar el dolor al reino del azar, a una zona eludible, de la que podemos escapar o por la que en todo caso no es necesario que seamos alcanzados». ${ }^{12} \mathrm{Se}$ muestra así una primera caracterización de esta relación, donde el hombre singular intenta rehuir o esconderse del dolor, quiere hacer del dolor algo negativo del que debemos renegar y dejar de lado, se podría decir, incluso que se hace del dolor algo calculable y disponible. Y bajo esos parámetros es que el dolor puede quedar oculto, escondido o, mejor dicho, debe ser negado, expulsado de la existencia. Sin embargo, sabe bien el autor, por su experiencia en la Primera

10 ibid, pp.13-17-18

11 ibid, p.13.

12 ibid, p. 15. 
Guerra Mundial, que a pesar de los intentos de renegar de esta experiencia su presencia y acoso es cierto e imposible de esconder, pues «nada nos es más cierto y nada nos está más predeterminado que cabalmente el dolor»». ${ }^{13}$ Esto muestra a las claras que nuestra relación con el dolor se ha trasformado, ha cambiado de categoría y debe ser evitado a cualquier coste.

Jünger sostiene en su interpretación de algunos cuadros del Bosco o de Cranach, que las máquinas que ahí aparecen son símbolos de la agresión disfrazada de máquina, y esta agresión, sería a su juicio la más fría e indiscriminada. Es decir, está reconociendo el carácter de esta amenaza de las máquinas como la más insaciable de todas, maquinaria bélica que se alimenta de la destrucción y aniquilación, donde se puede comprender que el dolor no presta atención no reconoce nuestro orden de valores y cualquiera, en cualquier momento, puede ser afectado o atacado por el dolor y el sufrimiento. ${ }^{14}$ En estas circunstancias el dolor no discrimina valores, ni personas, lo que acrecienta la sensación de nihilidad y vacío de la era técnica. En efecto, «el carácter indiscriminado de la amenaza se torna significativamente más visible en tiempos que solemos calificar de insólitos. En la guerra, cuando las balas pasan silbando a gran velocidad, junto a nuestro cuerpo, sentimos bien que ningún grado de inteligencia, virtud o coraje es lo bastante fuerte para apartarlas, aunque solo sea un pelo, de nosotros. A medida que aumenta la amenaza nos invade también la duda de la validez de nuestros valores $» .{ }^{15}$ Significa, entonces, que es en tiempos de penurias cuando tenemos esa relación cercana con el dolor, el sufrimiento, pues en cualquier momento nos puede alcanzar con sus garras y sentimos, por ende, que toda nuestra interpretación de la existencia y nuestros valores más importantes se tambalean y muestran su carácter perecedero. Esta es precisamente la amenaza proveniente de la industria bélica, que ha mostrado la peor cara del progreso técnico, donde se transforma la relación del hombre con el dolor y queda reflejado un crecimiento sustancial de su experiencia.

En este contexto, donde la vida humana y el planeta se encuentra amenazado por la maquinaria y técnica bélica crece la necesidad del hombre de dirigirse a una zona de confort que lo aleje del dolor y del sufrimiento, como fenómenos que deben ser desterrados de la vida. Como reconocerá Jünger más adelante la estrategia elegida para conseguir esta negación es brindar una aparente seguridad, bienestar y confort a través de la técnica, donde «la naturaleza de esa seguridad estriba, por tanto, en que el dolor es empujado a la periferia, en provecho de un mediano bienestar...la amenaza aumenta con cada una de las artificiosas elevaciones del dique que separa el ser humano de

13 ibid, p. 15.

14 Cf. ibid, p.17

15 ibid, p. 19

Contrastes vol. XXIII-N³ (2018) 
las fuerzas elementales...existen evidentemente actitudes que capacitan al ser humano para distanciarse muchos de las esferas donde el dolor manda como dueño absoluto. Semejante apartamiento se manifiesta en que el ser humano es capaz de tratar el cuerpo-es decir, el espacio mediante el cual participa en el dolor-como un objeto». ${ }^{16}$

Podemos ver de qué modo se lleva a cabo esta huída del dolor, que se da en forma de objetivación o cosificación del cuerpo y la existencia, donde a través de esta objetivación se pretende alejar el dolor de la vida humana y prevenirse contra él. Lo que se logra, en este contexto, con la utilización del uniforme, que sería justamente esa coraza que permite hacerle frente al dolor ocultándolo. Esta objetivación que se hace de la vida humana es una característica cierta de aquellos espacios donde el dolor se revela como una experiencia directa y se reconoce como un síntoma del crecimiento y desarrollo de los equipamientos bélicos. ${ }^{17}$ De esta manera el cuerpo y la vida humana se transforman y se consideran como un dispositivo más del mundo técnico, como una herramienta que debe encajar y someterse a las exigencias de la técnica, en este caso, militar.

Ahora bien, como sostiene Jünger, esta sería la mayor transformación que se viviría en la época técnica, donde la creciente objetivación de la existencia sería su característica más destacada y reflejo de dicho fenómenos, donde se hallaría, supuestamente, protegido del acoso del dolor. La técnica nos ofrece cierta protección contra el dolor, dado que «la técnica es nuestro uniforme. De todos modos, aún nos encontramos demasiado hundidos en este proceso como para poder abarcarlo en todo su extensión con la mirada...eso ocurre más cuanto que el carácter de confort de nuestra técnica está fusionándose de un modo cada vez más inequívoco con un carácter instrumental del poder». ${ }^{18}$ Es decir, la técnica con sus comodidades, con sus promesas de confort y bienestar, se convierte en el instrumento privilegiado para definir nuestra relación o experiencia con el dolor a través de la negación y el ocultamiento, donde la vida humana y el cuerpo son transformados en simples objetos de cálculo y planificación, donde el dolor no es aceptado y debe ser exorcizado. Asimismo cabe resaltar que en este escenario donde nos encontramos completamente inmersos, nos enceguece con esas promesas de seguridad técnica de tal forma que ni siquiera somos capaces de avizorar los peligros de este sometimiento técnico.

Ciertamente, el privilegio o el valor superlativo que se la ha dado a los instrumentos, a las técnicas sería la manifestación más clara y absoluta de esa creciente objetivación de la existencia, que en nuestros días adquiere un

16 ibid.pp. 33-34.

17 cf; p. 57.

18 Jünger, p. 59. 
cariz aún más peligroso, donde lo que importa no es respetar los valores que han construido al ser humano, pues en la construcción y comprensión de la existencia y el mundo «preponderan las valoraciones técnicas», donde puede esconder ese dolor en la medida que puede «extraerse a sí mismo de fuera de sí mismo. Ese extraer fuera de sí la vida, ese cosificarla y aumentarla, va aumentando sin interrupción». ${ }^{19}$

En último término, el nativo de Heidelberg, caracteriza a este tipo de hombre que se está formando al alero de la técnica como constituido por una segunda consciencia que es «más fría, está apuntando en la capacidad, cada vez más nítidamente desarrollada, de vernos como un objeto... se dirige a un hombre situado lejos de la zona del dolor» ${ }^{20}$ Esta sería la estratagema de la época técnica para situarnos en esa zona de confort, donde esta segunda conciencia crearía las circunstancias precisas para desarrollar hasta el límite la objetivación de la existencia y del mundo, donde todo debe estar sometido a ese proceso de reificación, situándonos en la periferia o, mejor dicho, lejos, aparentemente, del dolor.

Ahora bien, tal como dice Jünger nos encontramos en este contexto con un nuevo tipo de hombre, una nueva figura de la existencia, donde la técnica termina por cosificar la existencia para eludir el dolor y donde se aprecia «la modificación que está llevándose a cabo en la persona singular de transformación del individuo en tipo, o sea, en trabajador», ${ }^{21}$ todo esto entendido como «el proceso en el cual una nueva figura, la figura del trabajador, encuentra su expresión en tipo especial presentándose, por lo que se refiere a adueñarse del mundo, como la salida a escena de un principio nuevo que debe calificarse de Trabajo...ha de captar al trabajador con total independencia de las valoraciones, como portador de un tipo humano nuevo, y, de igual manera, el trabajo ha de presentársele por lo pronto como un nuevo modo de vivir, que tiene como objeto la superficie entera de la tierra». ${ }^{22}$ Desde esta óptica, el trabajo no es una actividad de carácter peculiar que lleva a cabo el hombre, como otras actividades que acomete diariamente, sino que más bien el trabajo es la manifestación de una forma especial de ser, donde no cabe más hablar de una diferenciación entre horas de trabajo y de descanso, pues este nuevo hombre no hay ninguna actividad que no se conciba como trabajo; a saber, en la era de la técnica el trabajo es la actividad que define y determina a la humanidad en su conjunto. Resume Jünger lo anterior de la siguiente forma, «la técnica es el 
instrumental, es la proyección de un modo especial de vida, para designar el cual es trabajo la expresión más sencilla». ${ }^{23}$

\section{TÉCNICA, TRABAJO Y DOLOR EN LA ERA DIGITAL.}

Una vez recogida la valoración de Jünger respecto a esta nueva figura de la humanidad que surge en la era técnica y que modifica su relación con el dolor, es necesario preguntar cómo se da esta experiencia en la actualidad, en la llamada era digital. Donde los avances y promesas tecnológicas de seguridad y bienestar están a la orden del día y prometen una estabilidad y felicidad a través del consumo ilimitado y las múltiples prestaciones que nos ofrecen las tecnologías de la información y las comunicaciones.

El pensador polaco Zygmunt Bauman parece recoger la interpretación jungeriana respecto de la creciente objetivación y cosificación de la vida humana que se da en la era del predominio de la técnica, pues en su interpretación de la vida contemporánea, definida como Modernidad Líquida o Vida de Consumo, afirma que la característica más sobresaliente de la sociedad consumista sería la capacidad que tiene esta de transformar al consumidor en producto de consumo, donde todos de alguna manera tenemos que vendernos como un producto de consumo apetecible y deseable, y tenemos al mismo tiempo que promover ese producto. Ahora bien, nos podemos preguntar: ¿Qué tiene ver todo esto con la objetivación de la existencia y el ocultamiento del dolor? Todo, pues Bauman sostiene que «en una grosera distorsión y perversión de la verdadera esencia de la revolución consumista, suele afirmarse que la sociedad de consumidores se centra en las relaciones entre el consumidor, firme en su estatus de sujeto cartesiano, y el producto, en el rol cartesiano de objeto...sin embargo, la sociedad de consumidores es lo que es precisamente porque no es así en absoluto. Lo que la singulariza y distingue de otros tipos de sociedad es justamente que las divisiones antes mencionadas son borrosas, y finalmente terminan por borrarse»». ${ }^{24}$ Lo que el pensador polaco viene a reconocer, al igual que Jünger, es que en la sociedad de consumidores todos quienes habitamos ese espacio nos transformamos en producto de consumo, es decir, en un objeto o mercadería más, lo que hablaría a las claras de esta creciente objetivación de la existencia; donde justamente se trata de ocultar esta cosificación de la existencia disfrazándola de libertad, soberanía y autodeterminación, donde la subjetividad del sujeto se construye a partir de las múltiples e interminables elecciones de consumo que nos ofrece el mercado a través del marketing.

En la llamada sociedad de la información todos debemos mostrarnos como un producto de consumo vendible para adquirir notoriedad y hacernos

23 ibid, p. 90.

24 Bauman 2009, p. 24. 
reconocibles y así salir de la invisibilidad. Para esta nueva figura de la vida humana, como producto u objeto, surge un instrumento privilegiado para dicha autopromoción: las redes sociales. Como sabemos bien las redes sociales, los teléfonos inteligentes, las aplicaciones tecnológicas se han transformado en lugar obligatorio para los miembros de la nominada era digital, donde se hace cada vez más difícil separar el mundo digital con el mundo de carne y hueso, como diría Unamuno. Afirma Bauman: «nuestra vida está entre dos universos, el online y el offline, y tiene definitivamente dos centros. Como nuestras vidas se mueven de un universo a otro $-\mathrm{y}$ cada universo tiene un contenido propio y unas reglas de actuación propias-, tendemos a utilizar el mismo material lingüístico cuando estamos en uno y en otro, sin ser consciente del cambio de campos semánticos en cada uno de ellos. Por consiguiente no se pude evitar la interpenetración. La experiencia obtenida en un universo acaba reformulando la axiología que guía los valores del otro. Una parte de la vida pasada en uno de los dos universos no se puede describir correctamente, y su significado no puede ser entendido, ni tampoco entendidas su lógica ni su dinámica, si referirse al papel que tiene, en su constitución, el segundo universo». ${ }^{25}$ Como resalta Bauman, las nuevas tecnologías traen aparejado un nuevo escenario donde el hombre termina sumido en una relación simbiótica entre el mundo online y el offline, donde cada vez es más difícil -quizás imposible -separar lo que pasa en una de lo que pasa en otra y por eso la mayoría de las veces los valores, la semántica y los actos que corresponden a una realidad, termina entremezclado con la otra, y muchas veces, por no decir la mayoría, lo que acontece en el mundo digital termina por determinar la vida offline. Esto tiene importantes consecuencias para el hombre contemporáneo, pues debe, obligatoriamente, hacer suyas ciertas exigencias que le imponen las nuevas tecnologías de la comunicación y esto incide directamente en su forma de experienciar el dolor.

Ahora bien, para poder acercarnos a esta experiencia fundamental, que está fuertemente marcada por la historia, correspondería a la era digital, definida por las nuevas tecnologías de la comunicación, tales como internet, las redes sociales, o apps de mensajería, una nueva experiencia del dolor, signada por las exigencias y requerimientos que surgen en esta era que nos toca vivir. Como recuerda Han, «al principio se celebró la red digital como un medio de libertad ilimitada...sugería una libertad y movilidad ilimitadas en la web. Pues bien, esta euforia inicial se muestra hoy como una ilusión. La libertad y la comunicación ilimitadas se convierten en control y vigilancia totales. También los medios sociales se equiparan cada vez más a los panópticos digitales que vigilan y explotan lo social de forma despiadada». ${ }^{26}$ Ciertamente la libertad, la seguridad,

25 Bauman 2013, p. 46.

26 Han 2014, p. 11.

Contrastes vol. XXIII-Nº3 (2018) 
el confort y la transparencia prometían ser los garantes de esta nueva forma de ser en el mundo. Sin embargo, a simple vista, parece que muchas de estas promesas han quedado en entredicho, pues la vigilancia, la mala utilización de los datos, cyberbulling, manipulación de los usuarios, postverdad, fake news, adicciones tecnológicas son el pan de cada día, lo que mostraría, a juicio del filósofo coreano, una problemática profunda de la era digital.

Respecto a estas transformaciones y su influencia en la contemporaneidad, señala Han «somos programados de nuevo a través de este medio reciente, sin que captemos por entero el cambio radical de este paradigma. Cojeamos tras el medio digital, que por debajo de la decisión consciente, cambia decisivamente nuestra conducta, nuestra percepción, nuestra sensación, nuestro pensamiento, nuestra convivencia. Nos embriagamos hoy con el medio digital, sin que podamos valorar por completo las consecuencias de esta embriaguez. Esta ceguera y la obnubilación constituyen la crisis actual». ${ }^{27} \mathrm{El}$ hombre contemporáneo se encontraría entonces sumergido en una crisis peculiar, causada principalmente por el desfase producido entre las promesas grandilocuentes de las utopías digitales y la realidad de sus manifestaciones, hoy más presentes que nunca. Sin embargo, no somos conscientes de estas transformaciones, ni siquiera hemos calibrado todavía las implicaciones de estos cambios y sus consecuencias, las que afectan profundamente nuestra existencia y la forma cómo nos relacionamos con el mundo y cómo nos relacionamos con el otro.

Es indiscutible que el desarrollo tecnológico, principalmente internet, ha traído consigo múltiples beneficios para la vida en sociedad, como un acceso instantáneo a la información, redes de comunicación ilimitada, redes de solidaridad planetaria, bases de datos, bibliotecas digitales, etc. Es decir, estas nuevas tecnologías han prometido como nunca una nueva relación con la libertad, donde podemos hacer lo que queramos en cualquier momento y en cualquier lugar, pues sentimos que tenemos todo al alcance de la mano. Y el instrumento que refleja esto en mejor medida es el teléfono móvil inteligente, que nos brinda toda esta infinidad de beneficios de manera ubicua.

En el smartphone, podemos reconocer de qué manera esa promesa de libertad absoluta termina convertida en una nueva forma de esclavitud posmoderna, donde nos sentimos completamente libres para interactuar y navegar en la red, soslayando completamente la coacción y vigilancia a la que somos sometidos, llegándose incluso a generar dependencias severas. Dice Han: «Hoy, en efecto, estamos libres de las máquinas de la era industrial, que nos esclavizaban y explotaban, pero los aparatos digitales traen una nueva coacción, una nueva esclavitud. Nos explotan de manera más eficiente por cuanto, en virtud de su movilidad, transforman todo lugar en un puesto de trabajo. La libertad de la

27 Han, 2014b, p. 6. 
movilidad se trueca por la coacción fatal de tener que trabajar en todas partes [...] el aparato digital hace móvil el trabajo mismo. Cada uno lleva consigo de aquí para allá el puesto de trabajo como un campamento». ${ }^{28} \mathrm{El}$ pensador coreano denuncia que estos instrumentos, que definen la era digital, comprometen al ser humano a otra relación con el trabajo, donde ya no existen las fronteras entre vida laboral y vida privada, entre tiempo de trabajo y de ocio, disfrazando bajo promesas de libertad, comunidad, comunicación ilimitada y libertad de información, un instrumento privilegiado de coacción y sometimiento, donde no es posible desconectar del trabajo o dejar de responder un mensaje urgente; «Ya no podemos escapar del trabajo». ${ }^{29}$

Este dispositivo inteligente como símbolo de la coacción del hombre contemporáneo reflejaría esa realidad transformada del homo digitalis, que intenta disfrazar este sometimiento con una apariencia de libertad, pues «hoy creemos que no somos un sujeto sometido, sino un proyecto libre que constantemente se replantea y se reinventa...la libertad, que ha de ser lo contrario de la coacción, genera coacciones. Enfermedades como la depresión y el síndrome de burnout son la expresión de una crisis profunda de la libertad...el sujeto del rendimiento, que se pretende libre, es en realidad un esclavo. Es un esclavo absoluto, en la medida en que sin amo alguno se explota a sí mismo de forma voluntaria». ${ }^{30}$ Han resalta de esta manera cómo en la era digital, la coacción, el sometimiento, la vigilancia se parapetan en una nueva especie de libertad, que viene asegurada por un ejército de dispositivos tecnológicos cuya función última sería precisamente esa: ser instrumentos de libertad y comunicación ilimitada.

Al mismo tiempo, se hace presente la manera en que el hombre de la era digital experiencia el dolor, pues esas exigencias que se autoimpone el sujeto del rendimiento que muchas veces no son cumplidas generan en él un sufrimiento profundo que se manifiesta en depresiones, o como dice Han, en el Síndrome de Burnout «o también conocido como síndrome de desgaste profesional, síndrome de sobrecarga emocional, síndrome del quemado o síndrome de fatiga en el trabajo fue declarado, en el año 2000, por la Organización Mundial de la Salud (OMS) como un factor de riesgo laboral, debido a su capacidad para afectar la calidad de vida, salud mental e incluso hasta poner en riesgo la vida del individuo que lo sufre»; 31 malestar que se muestra como una «dimensión de agotamiento emocional...despersonalización...reducción en la realización personal-que se refiere al declive en los sentimientos de competencia y de los

28 Han 2014, p. 41.

29 ibid.

30 Han 2014, p. 7

31 Saborio \& Hidalgo, «Síndrome de burnout», Medicina Legal de Costa Rica I (2015), Vol. 32, Costa Rica. 
buenos resultados en el propio trabajo, es decir, en una evaluación negativa de los logros personales en el trabajo...lo que genera que las personas se sientan descontentas consigo mismas e insatisfechas con sus logros en el trabajo»; ${ }^{32}$ queda así manifiesto el desfase entre la supuesta libertad, comunicación, incluso felicidad que prometen las tecnologías, con la nueva realidad del mundo contemporáneo como autoimposición del rendimiento y optimización de la vida humana y sus quehaceres, especialmente en su dimensión de trabajo. Instrumentos creados principalmente para estar sujetos y sometidos al trabajo sin tregua, donde la «optimización personal se muestra como la autoexplotación total $>.{ }^{33}$ Podríamos decir que no cumplir con esas exigencias de autopromoción, rentabilidad, rendimiento y optimización generan dolor y sufrimiento en la era digital, llegando incluso a poner en peligro la propia vida por no responder a las autoexigencias que gracias a la inteligencia del sistema neoliberal el hombre internaliza. Ahora bien, «al nuevo tipo de hombre indefenso y desprotegido... le falta toda soberanía. El hombre depresivo es aquel animal laborans que se explota a sí mismo, a saber: voluntariamente, sin coacción externa. Él es, al mismo tiempo, verdugo y víctima...la depresión se sustrae, sin embargo, de todo sistema inmunológico y se desata en el momento en el que el sujeto de rendimiento ya no puede poder más...no-poder-más-conduce a un destructivo reproche de sí mismo y a la autoagresión. El sujeto de rendimiento se encuentra en guerra consigo mismo y el depresivo es el inválido de esta guerra interiorizada. La depresión es la enfermedad de una sociedad que sufre bajo el exceso de posivitividad». ${ }^{34}$ Como bien expresa el pensador coreano el hombre de la era digital se siente libre de cualquier sometimiento, se supone como completamente soberano e independiente, es decir, solo se somete a sí mismo y a su voluntad. De esta manera el exceso de rendimiento y autoexplotación tiene carácter de una libre elección, lo que le brinda otra cara y la convierte en arma eficaz para aumentar la producción y optimización de la existencia y del trabajo, esto es, la apariencia de libertad. Profundizando en esto se debe precisar que: «una de las causas de la depresión, que a menudo acaba desembocando en el síndrome de burnout, es la excesiva, exagerada y pesada relación con uno mismo, que toma rasgos destructivos. El cansado sujeto del rendimiento también se atormenta a sí mismo. Está cansado, harto de sí mismo, de la guerra consigo mismo»; ${ }^{35}$ esto, por no cumplir con las expectativas y exigencias que ha internalizado de la sociedad neoliberal, que le exige éxito, estatus, notoriedad, felicidad. En

32 Díaz y Gómez, «La investigación sobre el síndrome de burnout en Latinoamerica entre 2000 y 2010» en Psicología desde el Caribe, (2016), Vol.33, n 1.

33 Han 2014, p. 27.

34 Han 2012, p. 19-20.

35 Han 2016, p. 25. 
definitiva, se identifica explotado con explotador y se sufre y experiencia el dolor como depresión o síndrome de burnout, pero esa agresión no se dirige hacia otro, ni hacia la sociedad, sino hacia sí mismo lo que produce una carga mayor de sufrimiento.

Precisamente esta autoexplotación se sustenta en que esta sociedad positiva no «admite ningún sentimiento negativo. Se olvida de enfrentarse al sufrimiento y al dolor, de darles forma. Para Nietzsche, el alma humana agradece su profundidad, grandeza y fuerza, precisamente, a la demora de lo negativo...el amor se doméstica y positiva como fórmula de consumo y confort. Hay que evitar cualquier lesión. El sufrimiento y la pasión son figuras de la negatividad. Ceden, por su parte, al disfrute sin negatividad. Y por otra parte, entran en su lugar perturbaciones psíquicas, como el agotamiento, el cansancio y la depresión, que han de atribuirse al exceso de positividad». ${ }^{36}$ Podemos ver como el dolor y el sufrimiento tienen que ser desechados y descartados, dado que en esta sociedad positiva la felicidad, el éxito son bienes deseables a cualquier costo y sacrificio, donde la seguridad y el confort que nos brindan las tecnologías desterrarían cualquier dejo de negatividad, de sufrimiento, pues, como sostiene Jünger, el uniforme del hombre contemporáneo es la técnica, que es de lo que se sirve la sociedad positiva, precisamente para ocultar este dolor, con aplicaciones, redes sociales, teléfonos inteligentes, interactividad, maratones de series, libros de autoayuda, inteligencia emocional, etc. En este mismo sentido se expresa Bauman, pues afirma que esta sociedad es la única donde no es posible legitimar o justificar la infelicidad, pues se niega a tolerarla y soportarla, y se convierte, así, en algo detestable. En efecto, «la infelicidad se transforma en un crimen punible, o en el mejor de los casos una pecaminosa desviación que descalifica a su portador de la membresía de buena fe de la sociedad». ${ }^{37}$

Si bien en la era digital de lo que se trata es de ocultar el dolor, el sufrimiento, la infelicidad, las debilidades, las disfunciones de carácter mental, teniendo como finalidad última la optimización personal que es coherente con la optimización del sistema termina quemando al hombre, se destruye y flagela a sí mismo, lo que lo lleva a una depresión que incluso lo puede llegar al suicidio. Sin embargo, como concluye el filósofo coreano, «la persona humana no se deja someter al dictado de la positividad. Sin negatividad, la vida se atrofia hasta el «ser muerto». Precisamente la negatividad mantiene la vida en vida. El dolor es constitutivo de la experiencia. Una vida que consistiera únicamente en emociones positivas o vivencias óptimas no sería humana. El alma humana debe su profunda tensión precisamente a la negatividad». ${ }^{38}$

36 Han 2013, p. 10.

37 Bauman 2009, p. 68.

38 Han 2014, p. 28

Contrastes vol. XXIII-Nº3 (2018) 


\section{ConClusión}

En definitiva, Han, al igual que Nietzsche y Jünger, piensa que, a pesar de que en la sociedad contemporánea, marcada por el progreso y desarrollo de la técnica, cuyo último estadio sería la era digital, se ha intentado disfrazar o desterrar el dolor de la existencia del hombre, principalmente a través de la seguridad, las comodidades, la interactividad que prometen las nuevas tecnologías de la comunicación, eso deriva en último término en depresiones o síndrome de burnout, como consecuencia, justamente, de esas exigencias, que a través de las tecnologías, le obliga e impone el sistema del rendimiento propio del neoliberalismo, que el homo de la era digital termina por hacer suyas y autoimponerse. Sin embargo, la existencia no se deja someter del todo a esto, pues el dolor, el sufrimiento, como experiencia fundamental, no puede ser expulsado o ignorado completamente, dado que es constitutivo esencial de la existencia, de su ir y venir en lo jocundo y adverso, como diría Ortega. Una existencia que no tuviera esos contrastes, esas dualidades, no sería propiamente un proyecto arrojado con todo lo que eso implica, no podría ser catalogado como vida humana. La vida es aquella tensión insuperable desde el nacimiento hasta la muerte, tensión entre la felicidad y la infelicidad, entre el dolor y el placer; tensión que define la vida de forma indefectible y considera al dolor como parte constitutiva esencial de ella y de su forma de ser en el mundo.

\section{REFERENCIAS BIBLIOGRÁFICAS}

BAUMAN, Z. 2009. Vida de consumo. Mexico: F.C.E. , 2013. Vigilancia liquida. Barcelona: Paidós.

JUNGER, E. 1990. El trabajador. Barcelona: Tusquets. , 1995. Sobre el dolor. Valencia: Pre-textos.

HAN, B.C. 2012. La sociedad del cansancio. Barcelona: Herder. , 2013. La sociedad de la transparencia. Barcelona: Herder. , 2014. Psicopolítica. Barcelona: Herder. , 2014 b. En el enjambre. Barcelona: Herder. , 2016. Topología de la violencia. Barcelona: Herder.

HEIDEGGER, M. 2000. Nietzsche II. Barcelona: Destino.

NIETZSCHE, F. 1985. La ciencia jovial. Caracas: Monte Ávila. , 1995. Más allá del bien y del mal. Madrid: Alianza. , 2004. Así habló Zaratustra. Madrid: Alianza. , 2008. Fragmentos póstumos IV. Madrid: Tecnos.

OCAÑA, M. 1997. Sobre el dolor. Valencia: Pre-textos. 
Dune Valle Jiménez es doctor en Filosofía en la Universidad de Salamanca (España). Grado de Filosofía, Universidad de Salamanca (España). Magister en Filosofía, con mención en Metafísica, Universidad de Chile. Profesor de Estado en Filosofía de la U.M.C.E (Chile). Obtuvo la beca Pre-doctoral de la Universidad de Salamanca. Su tesis doctoral, El problema ontológico del advenir como clave en el proyecto filosófico de Martin Heidegger recibió la distinción Sobresaliente «Cum Laude».

Se ha desempeñado como Colaborador Docente e Investigador Pre-doctoral de la Facultad de Filosofía, Filosofía de la Ciencia y Estética de la Universidad de Salamanca.

Actualmente es docente de la Escuela de Ciencias de la Comunicación de la Universidad Sergio Arboleda, Bogotá y profesor de posgrado en la Maestría en Filosofía Contemporánea de la Universidad de San Buenaventura, Bogotá.

Lineas de Investigación:

Su trabajo se ha dirigido principalmente al estudio de la hermenéutica y la fenomenología, la ontología y la metafísica, con énfasis en la filosofía temprana de Martin Heidegger. Actualmente trabaja sobre relación entre comunicación, ciencia y nuevas tecnologías.

Publicaciones recientes

VALLE, D. "La filosofía del joven Heidegger: la interpretación de la vida fáctica como dimensión fundamental de la hermenéutica", Cuadernos Salmantinos de Filosofia, Vol. 41, páginas 333-355. ISSN: 0210-4857.

VALLE, D. "La concepción del ser como presencia: el horizonte fundamental del proyecto de una ontología hermenéutico fenomenológica", Revista de Filosofía Odós, Vol. 2, Año 2, No 4. ISSN: 2322-8369.

E-mail

dune.valle@usa.edu.co 